\title{
Effect of Flow Direction on Relative Permeability Curves in Water/Gas Reservoir System: Implications in Geological $\mathrm{CO}_{2}$ Sequestration
}

\author{
Abdulrauf Rasheed Adebayo, ${ }^{1}$ Assad A. Barri, ${ }^{2}$ and Muhammad Shahzad Kamal ${ }^{1}$ \\ ${ }^{1}$ Center for Integrative Petroleum Research, King Fahd University of Petroleum \& Minerals, Dhahran 31261, Saudi Arabia \\ ${ }^{2}$ Petroleum Engineering Department, King Fahd University of Petroleum \& Minerals, Dhahran 31261, Saudi Arabia \\ Correspondence should be addressed to Abdulrauf Rasheed Adebayo; abdulrauf@kfupm.edu.sa
}

Received 29 March 2017; Revised 24 May 2017; Accepted 12 June 2017; Published 26 July 2017

Academic Editor: Weon Shik Han

Copyright (C) 2017 Abdulrauf Rasheed Adebayo et al. This is an open access article distributed under the Creative Commons Attribution License, which permits unrestricted use, distribution, and reproduction in any medium, provided the original work is properly cited.

\begin{abstract}
The effect of gravity on vertical flow and fluids saturation, especially when flow is against gravity, is not often a subject of interest to researchers. This is because of the notion that flow in subsurface formations is usually in horizontal direction and that vertical flow is impossible or marginal because of the impermeable shales or silts overlying them. The density difference between two fluids (usually oil and water) flowing in the porous media is also normally negligible; hence gravity influence is neglected. Capillarity is also often avoided in relative permeability measurements in order to satisfy some flow equations. These notions have guided most laboratory core flooding experiments to be conducted in horizontal flow orientation, and the data obtained are as good as what the experiments tend to mimic. However, gravity effect plays a major role in gas liquid systems such as $\mathrm{CO}_{2}$ sequestration and some types of enhanced oil recovery techniques, particularly those involving gases, where large density difference exists between the fluid pair. In such cases, laboratory experiments conducted to derive relative permeability curves should take into consideration gravity effects and capillarity. Previous studies attribute directional dependence of relative permeability and residual saturations to rock anisotropy. It is shown in this study that rock permeability, residual saturation, and relative permeability depend on the interplay between gravity, capillarity, and viscous forces and also the direction of fluid flow even when the rock is isotropic. Rock samples representing different lithology and wide range of permeabilities were investigated through unsteady-state experiments covering drainage and imbibition in both vertical and horizontal flow directions. The experiments were performed at very low flow rates to capture capillarity. The results obtained showed that, for each homogeneous rock and for the same flow path along the core length, the relative permeability and residual saturation are dependent on flow direction. The results were reproducible in all experiments conducted on the samples. This directional dependence, when accounted for in numerical simulation, can significantly improve simulation accuracy in the flow processes described.
\end{abstract}

\section{Introduction}

Reservoir rocks are often made of horizontal layers called sand beds that are usually interbedded with impermeable shales or silts that prevent cross flow between rock layers. As a result, flows in underground reservoirs are often considered to be principally in horizontal directions. In order to mimic reservoir flow conditions, laboratory flow experiments are often conducted with rock samples in horizontal orientation. However, there are field case scenarios where flows occur in vertical direction such as during water or gas flooding from horizontal well sections, gas upward/vertical migration due to buoyancy in thick rock beds during gas sequestration or gasenhanced oil recovery (EOR), and cross flow between reservoir beds with good vertical permeabilities. In such cases, modelling upward migration of $\mathrm{CO}_{2}$ plume or cross flow between reservoir beds using laboratory relative permeability data obtained from horizontal core flooding experiments will not be adequately representative and accurate. Furthermore, most commonly used relative permeability calculation methods are based on the assumption that two fluids flowing in the same direction are under pressure gradients that are 
relatively larger than the buoyant force of gravity as well as capillary forces. Hence, both gravity and capillarity are often neglected. Laboratory measurements conducted to obtain relative permeability and end saturations are thus required to obey such assumptions by conducting core flooding experiments at high flow rates such that viscous forces dominate and capillary forces are negligible. These assumptions also become invalid and greatly erroneous when studying a liquidgas system, where significant buoyancy exists because of the high variation in fluids densities. According to Corey [1], the assumption of neglecting both gravitational and capillary effects in the fractional flow equations is not accurate. He argued that capillary effect is not entirely eliminated and still exists during displacement process. He also pointed out that a large density difference occurs between water and oil in a soil-water system, which makes it impractical to ignore the gravitational terms. In addition, fluids' flow in actual reservoirs is mainly in capillary dominated regions with capillary number of $\leq 10^{-6}$. It is therefore essential to make laboratory measurements at conditions closely representative of reservoir conditions. This involves combining viscous, capillary, and gravity forces [2].

Bennion and Bachu $[3,4]$ did an extensive work on the role of lithology, permeability, and viscosity ratio on relative permeability in a horizontal core flooding of $\mathrm{CO}_{2}$ /brine system under different reservoir pressure and fluid conditions. Akbarabadi and Piri [5] conducted a $\mathrm{CO}_{2}$ /brine experiment with the rock samples in vertical position and flow in upward vertical direction under a capillary dominated flow regime. However, there was no comparative analysis of the effect of vertical flow on relative permeability and residual saturation as compared to the case when the flow is in horizontal direction. Niu et al. [6] investigated the effect of variation in pressure, temperature, and brine salinity on residual trapping of $\mathrm{CO}_{2}$ in a horizontal core flooding of Berea sandstones. Reynolds et al. [7] studied the effect of viscosity ratio and interfacial tension (IFT) under a capillary dominated flow regime of $\mathrm{CO}_{2}$ /brine system in a single Bentheimer sandstone sample flooded in a horizontal direction. Many other authors [8-11] investigated, through either simulation or laboratory experiment, the effect of flow rate/capillarity on multiphase flow of $\mathrm{CO}_{2}$ /brine in a horizontal core-flood. Many other published relative permeability curves considered only the effect of the viscous forces and neglected the contribution of capillary and gravitational forces. Few studies [12-14] have observed through experimental studies that relative permeability and end saturations are dependent on flow directions. However, the directional dependence of these parameters was thought to have been influenced by rock heterogeneity such as permeability anisotropy and presence of lamination. This study takes a step further to investigate whether the directional dependency of residual saturation and relative permeability are actually due to only the rock heterogeneity or also due to the flow direction and the dominating forces during the interplay between capillarity, viscous, and gravitational forces.

The objective of this study is to highlight the directional dependence of relative permeability and end saturations even for a homogeneous and isotropic system. This dependence,
TABLE 1: Sample properties.

\begin{tabular}{llcccc}
\hline Sample \# & Lithology & $\begin{array}{c}\text { Length } \\
(\mathrm{cm})\end{array}$ & $\begin{array}{c}\text { Diameter } \\
(\mathrm{cm})\end{array}$ & $\begin{array}{c}\text { Porosity } \\
(\%)\end{array}$ & $\begin{array}{c}k_{\text {brine }} \\
(\mathrm{mD})\end{array}$ \\
\hline Sample 1 & Sandstone & 30.3 & 3.8 & 19.49 & 158 \\
Sample 2 & Limestone & 25.4 & 3.8 & 13.88 & 269 \\
Sample 3 & Limestone & 25.4 & 3.8 & 11.83 & 79 \\
\hline
\end{tabular}

${ }^{*}$ Brine permeability was measured in horizontal orientation.

TABle 2: Fluid properties at 45 degree Celsius and atmospheric pressure.

\begin{tabular}{lccccc}
\hline & $\begin{array}{c}\text { Density } \\
(\mathrm{g} / \mathrm{cc})\end{array}$ & $\begin{array}{c}\text { Viscosity } \\
(\mathrm{cp})\end{array}$ & $\begin{array}{c}\text { Viscosity } \\
\text { ratio, } \\
\mu_{g} / \mu_{w}\end{array}$ & $\begin{array}{c}\text { Density } \\
\text { ratio, } \\
\rho_{g} / \rho_{w}\end{array}$ & $\begin{array}{c}\mathrm{IFT}, \sigma_{g w} \\
(\mathrm{dyn} e \mathrm{~cm})\end{array}$ \\
\hline Brine & 1.0204 & 0.5653 & 0.0329 & 0.1019 & 62 \\
Nitrogen & 0.104 & 0.0186 & & & \\
\hline
\end{tabular}

$\mu_{g}$ and $\mu_{w}$ denote the viscosity of gas and water, while $\rho_{g}$ and $\rho_{w}$ denote the density of gas and water. IFT denotes interfacial tension between gas and water and is denoted by $\sigma_{g w}$.

when accounted for in numerical simulation, can significantly improve simulation accuracy in flow processes involving vertical flow. Finally, it should be noted that directional flow as meant in this study may not necessarily be only due to directional permeability caused by heterogeneous features like anisotropy or laminations, as these have been sufficiently discussed in the literature [12-15]. In the context described here, the variations in relative permeability and residual saturation exist due to flow direction even if the rock is very homogeneous and has an isotropic permeability.

\section{Experimental Procedures}

Experiments were conducted using three samples, which include sandstone and limestone obtained from Berea sandstones and Indiana limestone, respectively. The porosities of the samples range from $11.8 \%$ to $19.5 \%$, while the liquid permeabilities range from $79 \mathrm{mD}$ to $270 \mathrm{mD}$ as seen in Table 1. Soxhlet reflux extraction method was used to clean samples at elevated temperature of $80^{\circ} \mathrm{C}$ and then dried in a vacuum oven at $60^{\circ} \mathrm{C}$. Table 1 summarizes the samples' dimensions and physical properties. Synthetic aquifer brine was prepared with TDS of $58 \mathrm{~g} / \mathrm{l}$ and a density of $1.03 \mathrm{~g} / \mathrm{cc}$ and high purity (99.9\%) Nitrogen was used as the gas phase. Nitrogen gas was used instead of $\mathrm{CO}_{2}$ to avoid complexities in saturation estimation because of mass transfer and active rock fluid interaction. However, the results obtained using gas can be applicable to other gases such as $\mathrm{CO}_{2}$. The fluids properties were measured at $45^{\circ} \mathrm{C}$ and at atmospheric pressure as given in Table 2.

2.1. Description of Experiments. A series of unsteady-state and low flow rates core flooding experiments were performed to represent actual flow conditions during $\mathrm{CO}_{2}$ injection in saline aquifer, using the set-up shown in Figure 1. The 


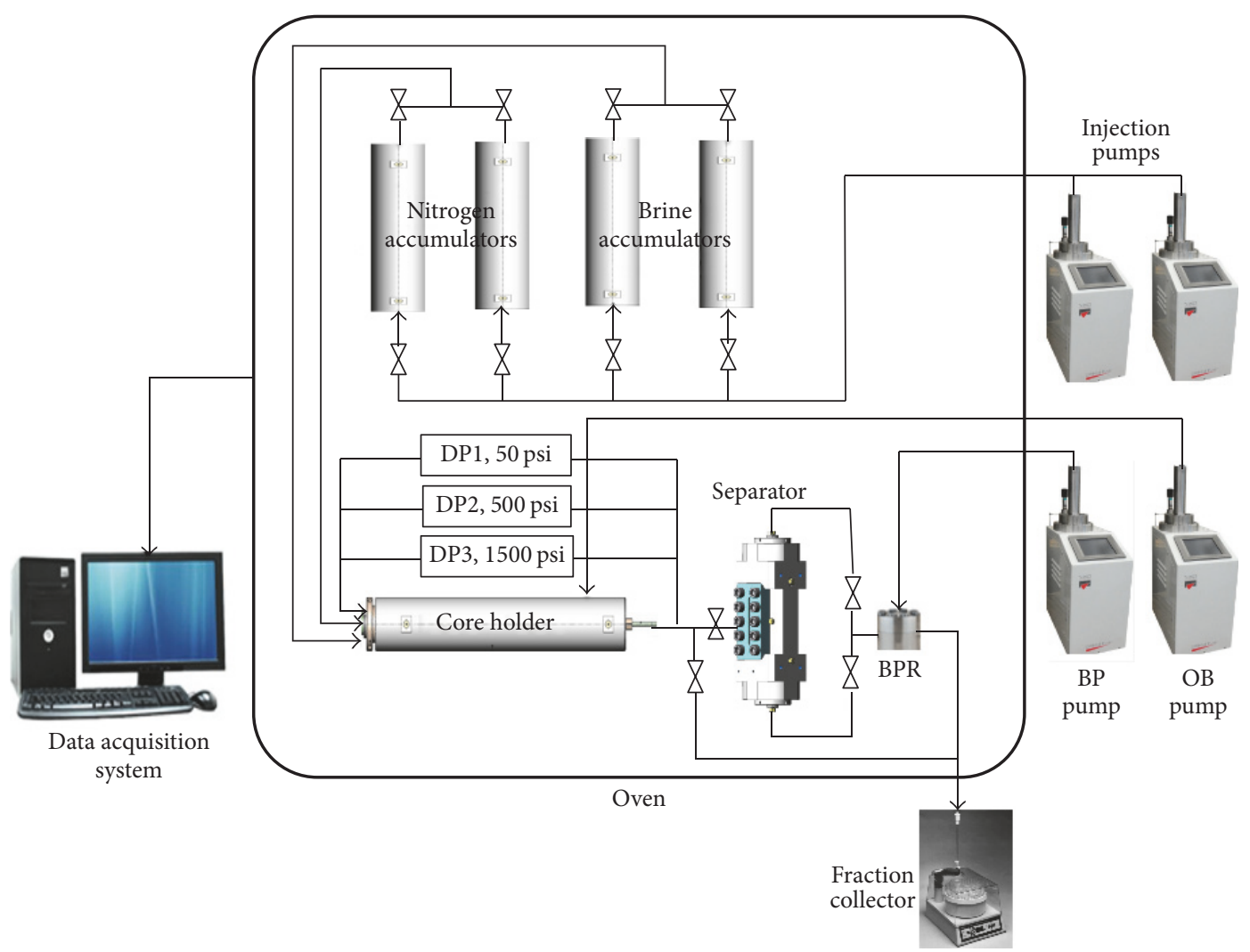

FIGURE 1: Experimental setup. BPR is backpressure regulator, BP means backpressure, and OB is overburden pressure.

core holder is a hydrostatic core holder, which holds the cylindrical rock sample, and is capable of applying a confining pressure on the sample. It can be rotated such that core flooding is conducted in either horizontal or vertical orientation. The core holder is also capable of holding samples of varying lengths as long as $30.48 \mathrm{~cm}$ with diameter of $3.8 \mathrm{~cm}$. Reservoir fluids (brine and nitrogen) were stored in floating piston accumulators made of Hastelloy and stainless steel. A dual injection pump is connected to the accumulators through stainless steel tubing. The pump was used to drive fluid from the floating piston accumulators into the core sample through another set of stainless tubing connecting the accumulators to the core holder. The injection pump is capable of continuous fluid injection at a specified constant rate $(0.01-50 \mathrm{cc} / \mathrm{min})$ and injection pressure as high as 10,000 psi. Another automated syringe pump was used to supply a constant confining pressure of 2,000 psi (or net confining pressure of $450 \mathrm{psi}$ ) on the sample, while a third pump was used to provide a constant backpressure of 1,450 psi. A video separator is placed between the backpressure regulator and the core outlet to record the amount of fluid produced from the sample. High-resolution differential pressure transducers $( \pm 50 \mathrm{psi}$, $\pm 500 \mathrm{psi}$, and $\pm 1,500$ psi with resolutions of $\pm 0.1 \%$ of full scale) were used to measure the pressure drop across the samples. An industrial oven encloses and applies constant temperature of $45^{\circ} \mathrm{C}$ on all the accumulators, core holders, separator, and tubing. Fluid flow into the sample was controlled and alternated with air actuated automated pneumatic valves. All core flooding data such as rates, pressure gradient, oven temperature, backpressure, overburden pressure, and fluid production were continuously recorded at a stipulated time interval of 5 seconds on a computer station.

The samples were presaturated with the formulated brine using vacuum saturation method. Each sample was subsequently placed in the core holder and circulated with about $2 \mathrm{PV}$ of brine at a constant injection rate of $0.5 \mathrm{cc} / \mathrm{min}$. This was to ensure that all trapped gases are removed and the sample comes to thermodynamic equilibrium with the brine. Absolute permeability of brine was measured on each sample in both horizontal and vertical flow orientations. The procedure involved measurement of pressure drop across the sample at different flow rates. Darcy's equation was then used to compute the absolute permeability from a linear plot of pressure gradient versus flow rates. At the end of permeability measurement, the flow rate was reduced back gradually to $0.5 \mathrm{cc} / \mathrm{min}$ and allowed to stabilize. Afterwards, unsteadystate drainage and imbibition experiments were conducted on each rock sample at a constant injection rate of $0.5 \mathrm{cc} / \mathrm{min}$ and at other experimental conditions mentioned above. Drainage involved injecting gas to displace the brine from the sample until a stabilized flow and irreducible water saturation were attained. Imbibition then followed by injecting brine to displace the gas until residual gas saturation was attained. Stabilized flow at irreducible/residual fluid saturation is indicated by stabilized pressure drop and production curve. Core flooding experiments were repeated multiple times with the 


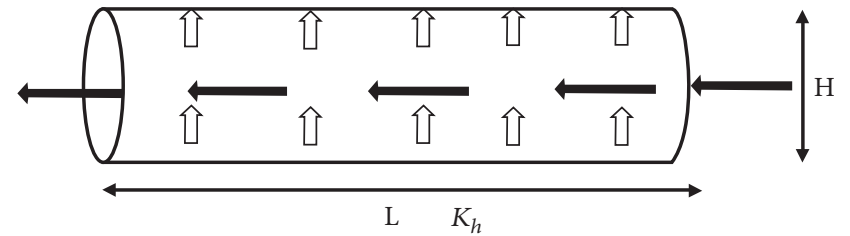

(a)

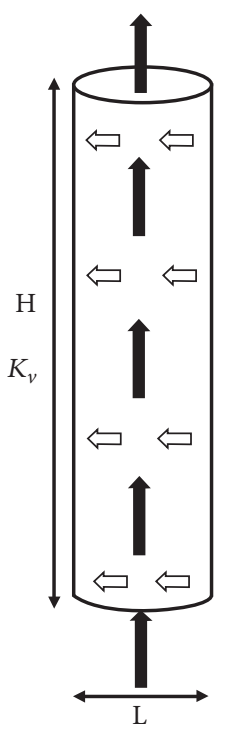

(b)

FIGURE 2: Illustration of flow directions during (a) horizontal flow and (b) vertical upward flow for the same sample.

same fluids and the same experimental conditions but with different flow directions in order to isolate the effect of heterogeneity and permeability anisotropy. In this way, comparison can be fairly made between horizontal and vertical flows without the influence of rock heterogeneity and anisotropy.

2.2. Dimensionless Number. Dimensionless numbers were used to characterize the flow behavior in both horizontal and vertical flows. Different dimensionless numbers exist such as those derived by Fulcher et al. [16], Zhou et al. [17], Chia-Wei and Sally [18], and Reynolds and Krevor [19]. In this paper, we use capillary number as given by Fulcher et al. [16] in (1) and gravity number given by Zhou et al. [17] in (2). The gravity number in (2) was used because it can be used to compare the ratio of the forces acting in transverse and longitudinal direction in horizontal flow as in Figure 2(a) with that where the principal flow direction is vertically upward as in Figure 2(b). In case (a), gravity and capillary effect are associated with the vertical direction $(\mathrm{H})$, while viscous effect is associated with the horizontal direction (L) (i.e., direction of pressure drop). Hence, (2) was used to compute the gravity number. In Figure 2(b), both viscous and gravity forces are associated with $\mathrm{H}$, while capillary force can drive flow in $\mathrm{L}$ direction. Hence, the ratio of fluid flow in the vertical direction $(\mathrm{H})$ due to gravity and viscous force to that in horizontal direction (L) due to capillary forces is thus given in (3).

$$
\begin{aligned}
N_{c a} & =\frac{\mu_{g} V_{t}}{\sigma_{g w}}, \\
N_{g v \text { (hori) }} & =\frac{L g K_{h} \Delta \rho_{g w}}{H \mu_{g} V_{t}}, \\
N_{g v \text { (vert) }} & =\frac{K_{v} g \Delta \rho_{g w}}{\mu_{g} V_{t}},
\end{aligned}
$$

where $H$ is height or vertical distance through which fluid flows, $L$ is the distance the fluid flows in horizontal direction, $K$ is absolute permeability in the transverse flow direction ( $K_{h}$ in case (a) and $K_{v}$ in case (b) in Figure 2) in $\mathrm{mD}, V_{t}$ is total flow velocity in the principal flow direction in $\mathrm{m} / \mathrm{s}, \mu_{g}$ is gas viscosity in cp, $g$ is acceleration due to gravity in $\mathrm{m} / \mathrm{s}^{2}, \sigma$ is interfacial tension in $\mathrm{N} / \mathrm{m}$, and $\Delta \rho_{g w}$ is density difference between gas and brine in $\mathrm{Kg} / \mathrm{m}^{3}$.

2.3. Relative Permeability Models. Since the experimental conditions under which the experimental data presented above were obtained violate the assumption of Weldge, Johnson-Bossler-Naumann (JBN) method, and other explicit relative permeability methods, empirical correlations are used to generate the relative permeability curves for the different flow processes. The two most commonly used empirical correlations are Corey's [20] two-phase relations (theoretical approach) for drainage in a consolidated rock and Naar and Henderson's [21] two-phase model for imbibition. Corey's [20] model is given as follows:

$$
\begin{aligned}
S_{w}^{*} & =\frac{S_{w}-S_{i w}}{1-S_{i w}}, \\
k_{r w} & =\left(S_{w}^{*}\right)^{((2+3 \lambda) / \lambda)}, \\
k_{r n} & =\left(1-S_{w}^{*}\right)^{2}\left(1-\left(S_{w}^{*}\right)^{((2+\lambda) / \lambda)}\right),
\end{aligned}
$$

where $k_{r n}$ and $k_{r w}$ are the nonwetting and wetting phase relative permeabilities, respectively, $S_{w}^{*}$ is the normalized wetting phase saturation, $\lambda$ is the pore size distribution index, $S_{w}$ is the water saturation, $S_{i w}$ is the irreducible water saturation, and $S_{r n w}$ is the residual nonwetting phase saturation. The pore size distribution index, $\lambda$, was obtained 


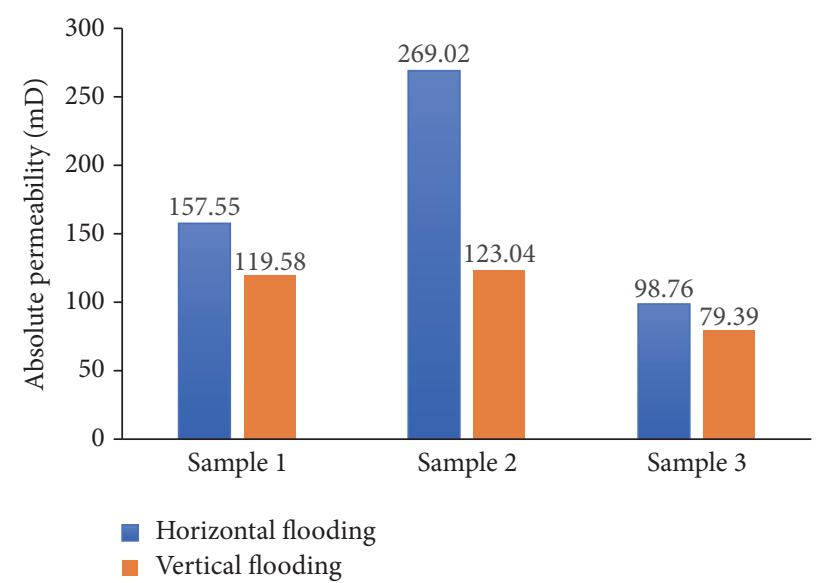

FIGURE 3: Absolute permeability to brine for horizontal and vertical core orientation.

empirically from capillary pressure data using Brooks and Corey [22], which relates capillary pressure to normalized wetting phase saturation.

$$
\log P_{c}=\log P_{e}-\frac{1}{\lambda} \log S_{w}^{*},
$$

where $P_{c}$ is the capillary pressure, $P_{e}$ is the minimum threshold pressure, and $S_{w}^{*}$ is the normalized water saturation. Naar and Henderson's [21] two-phase model for imbibition is given as follows:

$$
\begin{aligned}
k_{r w} & =\left(S_{w}^{*}\right)^{((2+3 \lambda) / \lambda)}, \\
k_{r n} & =\left(1-2 S_{w}^{*}\right)^{3 / 2}\left[2-\left(1-2 S_{w}^{*}\right)^{1 / 2}\right] .
\end{aligned}
$$

In this study, a $\lambda$ value of 2 was used for all the samples assuming that they fall within Wyllie's equation for cemented sandstones and oolitic and small vug limestone. This value is sufficient for approximation purpose, since the intent is to show how flow direction influences relative permeability for the same rock sample. The value used does not affect the comparison between vertical and horizontal flows, since the same rock samples were used for both flow directions.

\section{Results and Discussions}

The absolute permeability values of brine for the three samples are shown in Figure 3. The absolute permeabilities of brine in horizontal and vertical core flooding, respectively, are compared. It can be seen that $K_{V}$ was lower than $K_{H}$. This is due to the gravity term and higher pressure gradient required to overcome gravity force during $K$ measurements. Dimensionless numbers (see (1), (2), and (3)) were then used to characterize the different flow experiments in the three samples, namely, horizontal drainage, horizontal imbibition, vertical drainage, and vertical imbibition.

3.1. Residual Saturation. As discussed earlier, the cross plot of residual saturation versus capillary number is a very useful

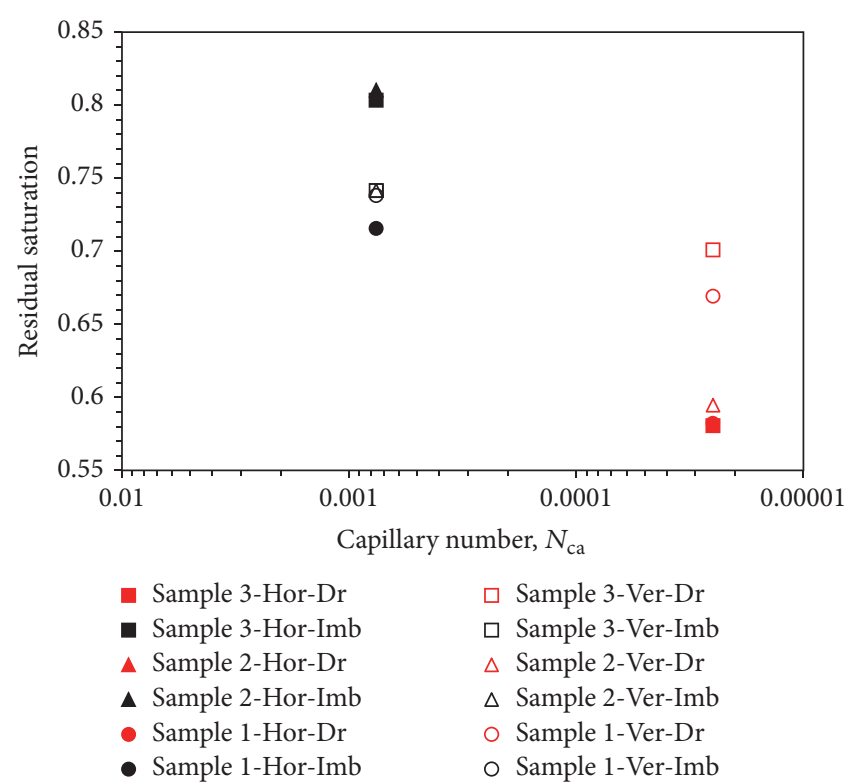

FIGURE 4: Residual saturation versus capillary number for horizontal and vertical flow. "Hor" means horizontal, "Ver" means vertical, "Dr" means drainage, and "Imb" means imbibition.

tool in understanding the interplay between viscous and capillary forces. It explains how these forces affect residual saturation during immiscible displacements in rock samples. The capillary number for all the flow experiments conducted in this study was computed using (1) to get a capillary number of $0.8 \times 10^{-5}$ for both vertical imbibition and horizontal imbibition and $2.5 \times 10^{-5}$ for both vertical drainage and horizontal drainage as seen in Figure 4. The capillary numbers were the same because the same values of injection rates, fluid pairs, and experiment conditions were used in both flow directions. In addition, the range of capillary number for both drainage and imbibition is within the capillary dominated flow range in actual reservoir flow. According to Willhite [23], capillary dominated flow processes have capillary number in the range of $\sim 10^{-6}$. Gravity number, on the other hand, can be seen in Figure 5 to vary from sample to sample and from vertical flow to horizontal flow because of the effect of gravity and permeability variation from sample to sample and from vertical flow to horizontal flow. The gravity number relates the effect of gravity force to viscous force according to (2). As seen in Figure 5, increasing gravity number resulted in lower residual/irreducible saturations in all the samples and flow experiments. The higher gravity numbers are for the horizontal flows, while the lower ones are for the vertical flow experiments. A Lower gravity number means that gravity was not in favor of flow and hence the observed higher residual saturations. Similarly, a high gravity number means that gravity dominates and was in favor of flow. The work of Kuo and Benson [10] also showed that a higher gravity number resulted in a lower residual saturation and vice versa.

The cumulative fluid productions during drainage are also shown in Figures 6-8 for both vertical and horizontal core flooding. For drainage process, it can be seen that 


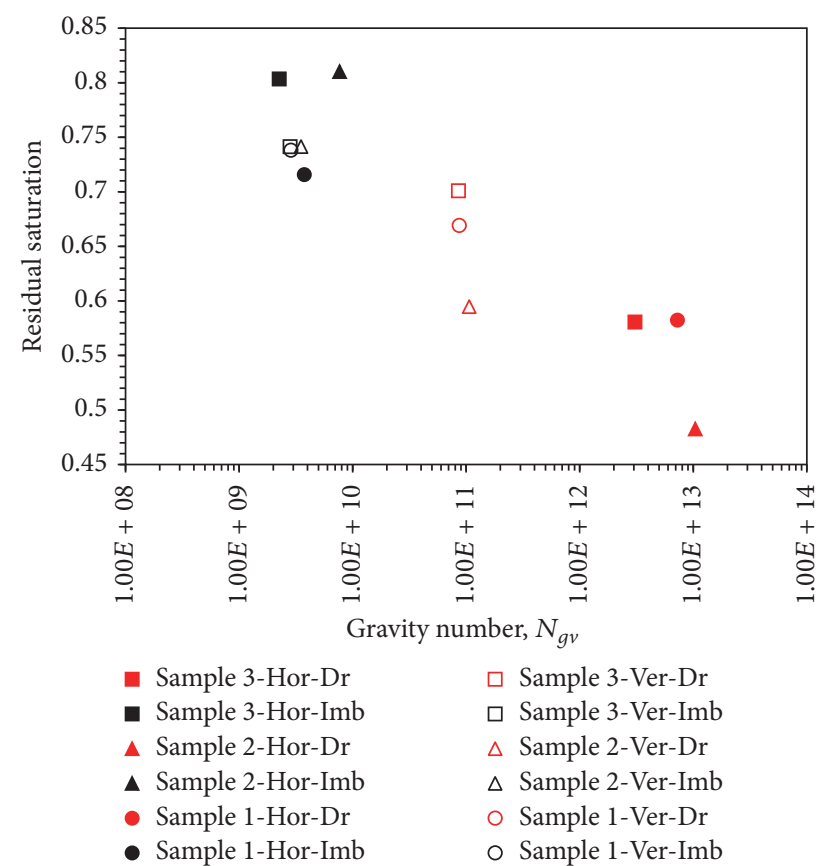

FIGURE 5: Residual saturation versus gravity number for horizontal and vertical flow. "Hor" means horizontal, "Ver" means vertical, "Dr" means drainage, and "Imb" means imbibition.

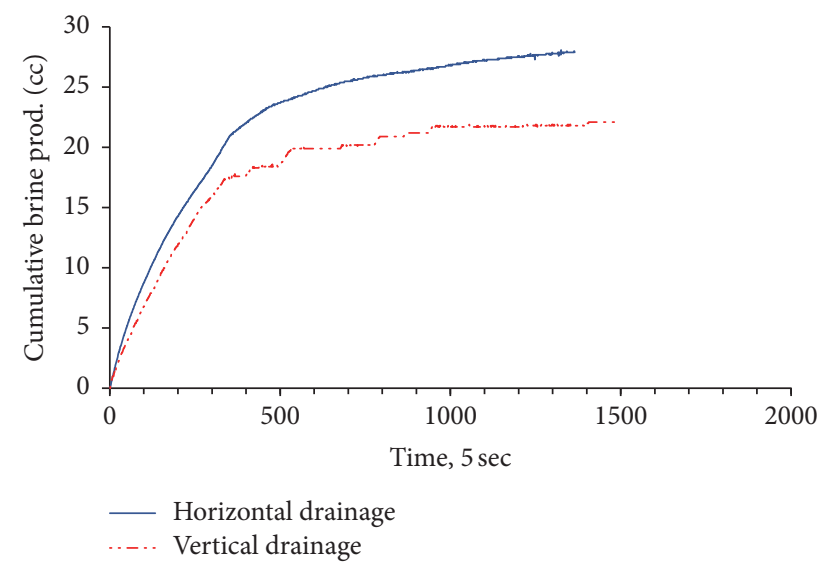

FIGURE 6: Comparison of cumulative brine production during gas injection in horizontal and vertical core flooding in sample 1.

horizontal core flooding yielded more brine production (i.e., lower residual water saturation) than when the same core sample was flooded from bottom to top in a vertical core orientation. The gravity number in horizontal flow is higher than that in vertical flow. Moortgat et al. [24] observed a similar gravitational effect during their study in which oil recovery was compared between core flooding in horizontal, vertical up, and vertical down $\mathrm{CO}_{2}$ flooding. In their study, $\mathrm{CO}_{2}$ density was higher than the oil density used; hence, gravitational frontal instability was observed during vertical $\mathrm{CO}_{2}$ injection from top to bottom. In our study, gravitational instability was observed during nitrogen

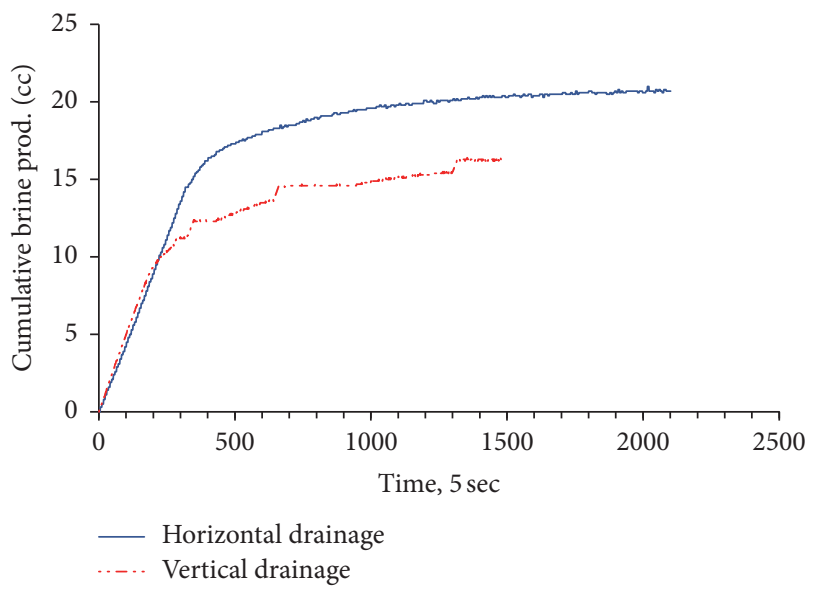

FIGURE 7: Comparison of cumulative brine production during gas injection in horizontal and vertical core flooding in sample 2.

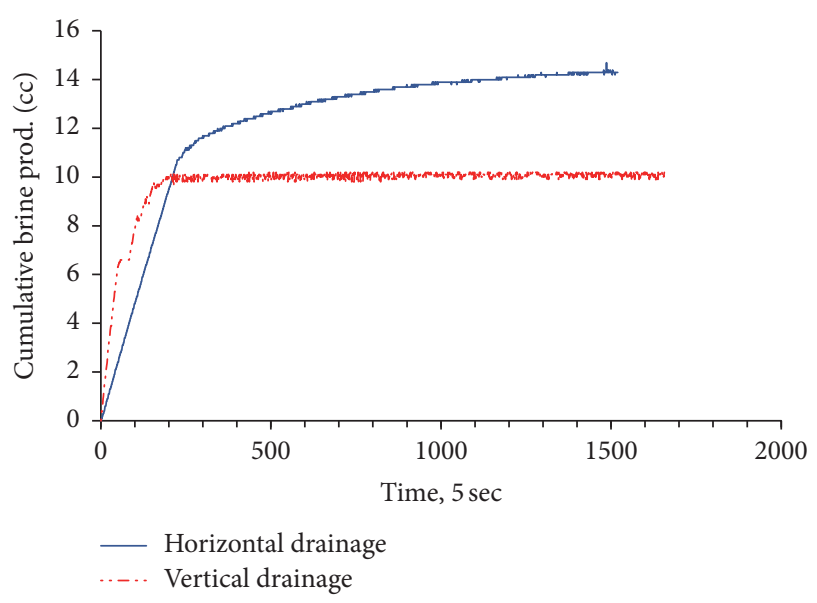

FigURE 8: Comparison of cumulative brine production during gas injection in horizontal and vertical core flooding in sample 3.

injection from bottom to top because nitrogen density is much lower than brine density. Gravitational fingering will be significantly higher during vertical multiphase flow of two fluids of wide density difference than during horizontal multiphase flow of the same fluid pair in the same sample and at the same experimental conditions. Because of the wide difference in fluids' density and the very low injection rates, gravitational fingering caused by gravity segregation dominated the flow process in comparison to viscous and capillary forces. Since the injection rate is quite low, the viscous force is weak and is unable to overcome the gravity effects; hence, some of the residual brine in the rock sample gradually replaces the injected gas at the bottom (causing a downward flow). Since the core sample is quite long and the injection rate is low, fluid segregation and replacement have sufficient time and space to take place. Furthermore, the rate of fluid segregation and replacement may be higher than the rate of brine production, a possible phenomenon that may explain the lower recovery from vertical upward 


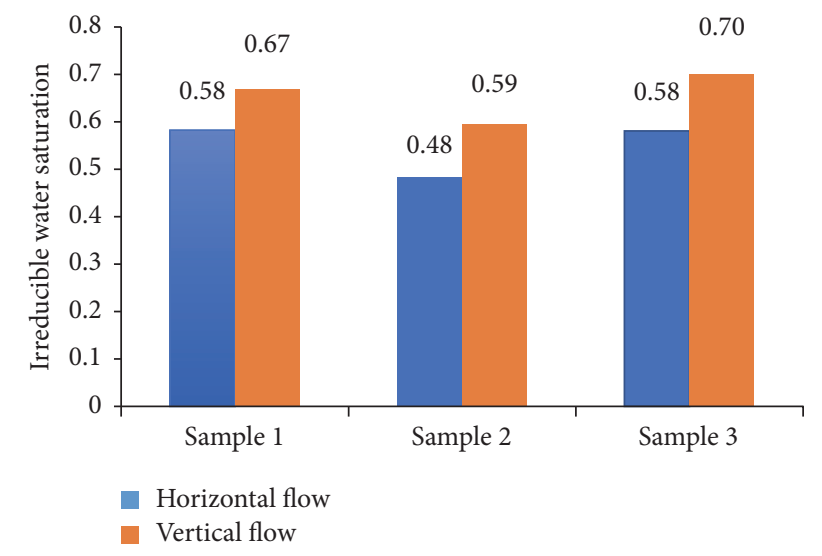

Figure 9: Comparison of irreducible water saturation during horizontal drainage and vertical drainage.

flow and the production rate not being equal to the injection rate as can be observed in the production curves in Figures $6-8$. The irreducible water saturations after vertical drainage and horizontal drainage are also compared in Figure 9. It can be seen in the figure that the irreducible water saturation in vertical flow is higher than that in the horizontal flow. The reason is obviously due to the gravity fingering of gas during gas injection from the bottom to the top of the sample, which resulted in an unstable displacement. As discussed above, the very low injection rate allowed gravity segregation to dominate both viscous and capillary forces, causing the water in the sample to settle down to replace the injected gas instead of being produced at the outlet; hence, not much water is produced from the top.

For gas-EOR methods in horizontal wells, gravity fingering effect can be dampened by injecting the gas at an optimum high injection rate. High injection rates can be achieved only at the near wellbore area, while the far field area will continue to be in the low flow rate regime. Another method of dampening gravity fingering is by designing the well completion such that the injection well is placed at the top and production well at the bottom so that injected gas sweeps the oil from top to bottom. In the case of gas sequestration such as $\mathrm{CO}_{2}$ sequestration, a low injection rate in a vertical upward flow will be most desirous, since the optimum goal is to increase the amount of gas trapped permanently. Gravity fingering will thus facilitate capillary trapping of the injected gas. The optimum injection rate that will cause the maximum residual gas saturation will be sought through a dimensionless-saturation correlation. A study to derive these correlations is ongoing.

Figures 10-12 show the cumulative gas recovery during secondary imbibition. Similar to drainage experiments, recovery during horizontal flooding is also consistently higher than recovery during vertical flooding. The higher gas recovery observed in the horizontal core flooding during secondary imbibition can be explained by the initial-residual (IR) gas theory. That is, the higher the initial gas saturation, the higher the recovered gas. The gas injected in the horizontal core flooding was higher than that injected during

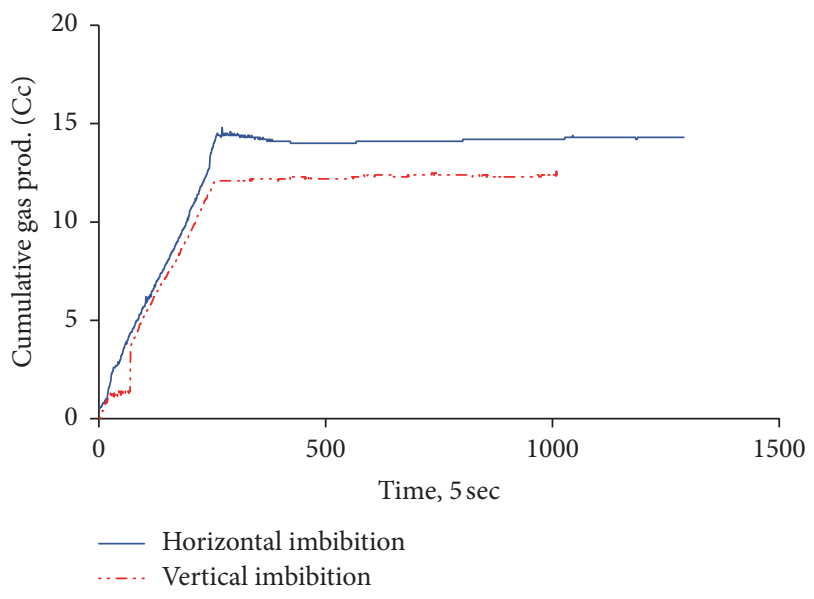

Figure 10: Comparison of cumulative gas production during secondary brine injection in horizontal and vertical core flooding in sample 1.

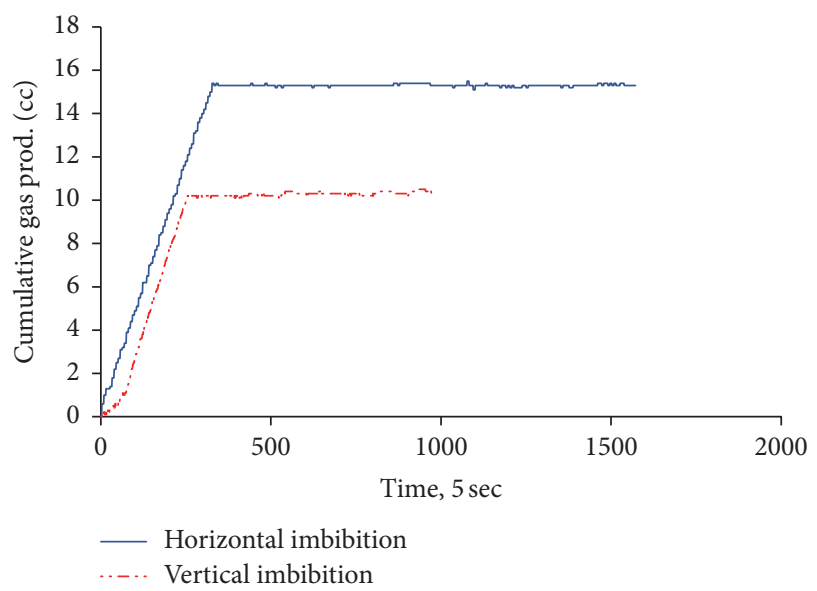

FIGURE 11: Comparison of cumulative gas production during secondary brine injection in horizontal and vertical core flooding in sample 2 .

vertical flooding because a lower irreducible water saturation was attained during horizontal injection. Figure 13 compares the residual gas saturation in horizontal and vertical flow directions. One would expect that, under the same initial gas saturation, vertical upward water injection would give higher gas recovery than the horizontal flow because of the expected more stable displacement front. However, because the initial gas saturation during horizontal drainage is quite higher than the initial gas saturation during vertical drainage for a given sample, the horizontal imbibition experiment will produce more gas than the vertical secondary imbibition experiments on the same sample. This then explains the higher recovered gas (Figures 10-12) or higher trapped gas saturation (Figure 13) during horizontal flow. Another important feature of the imbibition process is the pistonlike displacement of the gas as manifested in the production curves. The production curves sharply progressed from a linear increase to no production (a flat and stable line). 


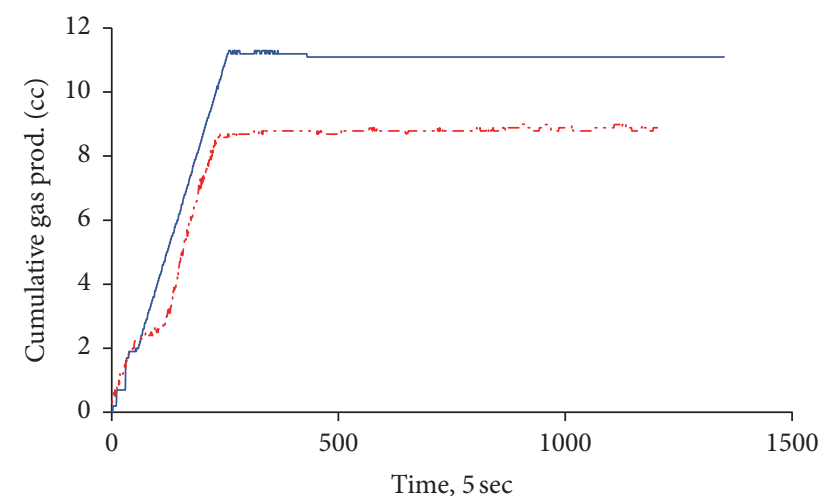

- Horizontal imbibition

..... Vertical imbibition

FIGURE 12: Comparison of cumulative gas production during secondary brine injection in horizontal and vertical core flooding in sample 3.

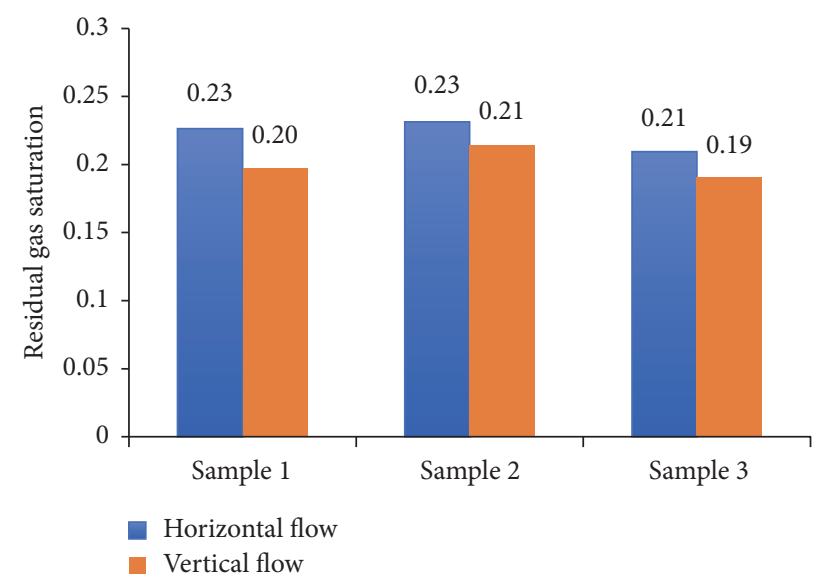

FIGURE 13: Comparison of residual gas saturation during horizontal and vertical secondary imbibition.

3.2. Relative Permeability Curves. The relative permeability curves are generated for each sample, using (4) to (7). As can be seen from these equations, relative permeability is strongly dependent on the end saturation values. Since end saturation in vertical flow differs from that in horizontal flow for the same sample, the relative permeability curves will also differ accordingly as shown in Figures 14-16. The relative permeability of all the samples tested showed strong dependence on flow direction. Such difference in relative permeability and end saturation can have significant bearing on the numerical simulation carried out in forecasting $\mathrm{CO}_{2}$ distribution (in the case of $\mathrm{CO}_{2}$ sequestration) or recovery (in the case of EOR). For example, the predicted $\mathrm{CO}_{2}$ saturation distribution and $\mathrm{CO}_{2}$ travel time may be either significantly underestimated or overestimated. It is therefore crucial that the right relative permeability curves are selected which are representative of the actual flow direction in a reservoir.

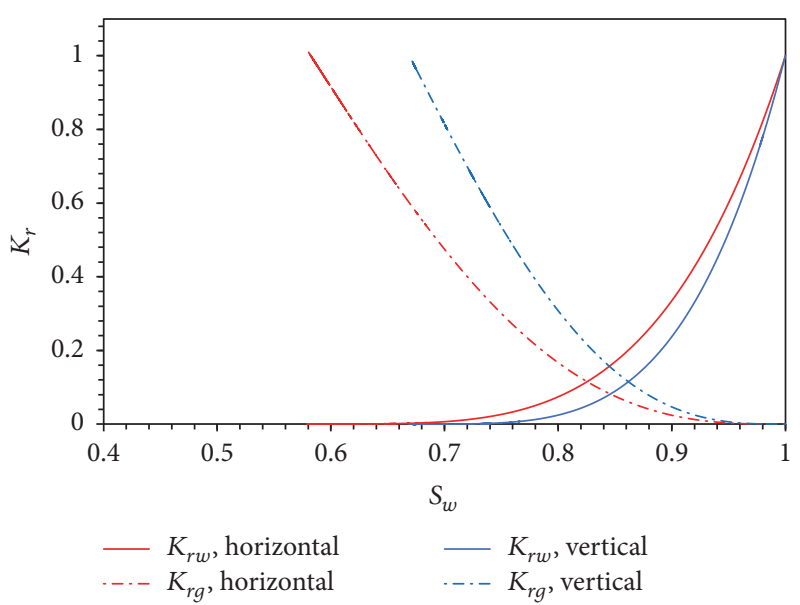

(a)

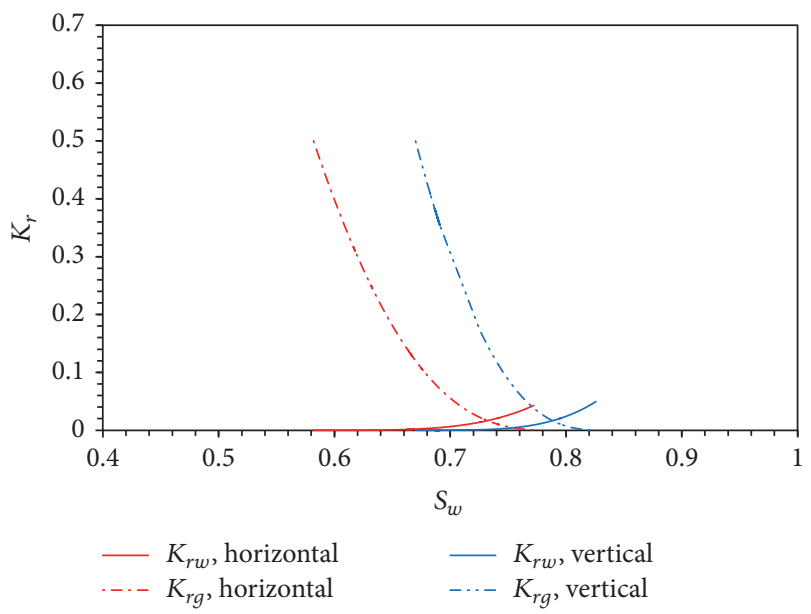

(b)

FIGURE 14: Comparison of relative permeability curves: (a) drainage and (b) imbibition for sample 1.

\section{Conclusions}

In this study, a reservoir condition core flooding experiments were conducted in two flow directions, namely, horizontal and vertical flows. The flow conditions capture unsteadystate flow, gravity, and capillarity that are common in actual field scenario but are often neglected in many laboratory estimations of relative permeability of gas-liquid systems. The following conclusions are drawn from this study:

(1) Directional dependence of relative permeability and end saturations is not only due to heterogeneity (caused by permeability anisotropy and heterogeneity) but also due to the flow direction itself as observed in homogeneous and isotropic rocks tested.

(2) Residual fluid saturation is higher when flow is in vertical direction as compared to horizontal flow direction even in an isotropic rock.

(3) The interplay between viscous and gravity forces during flow in horizontal and vertical directions as 


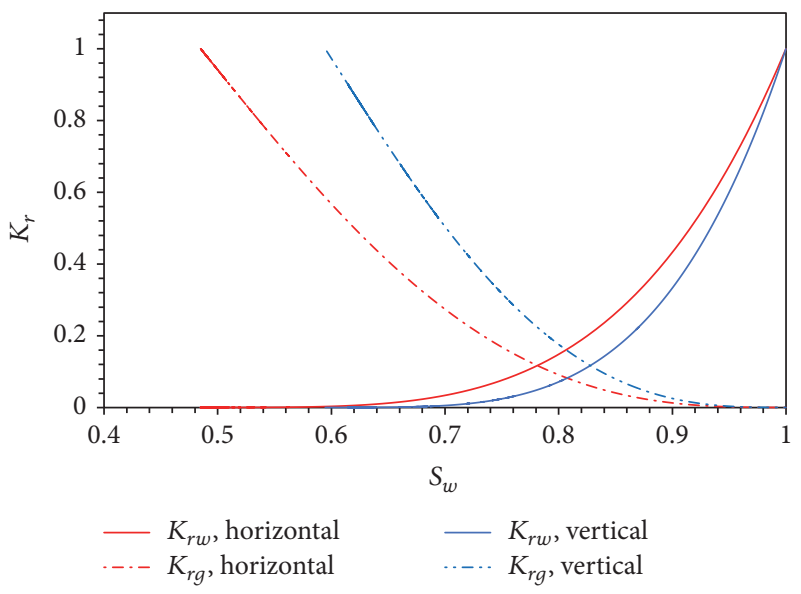

(a)

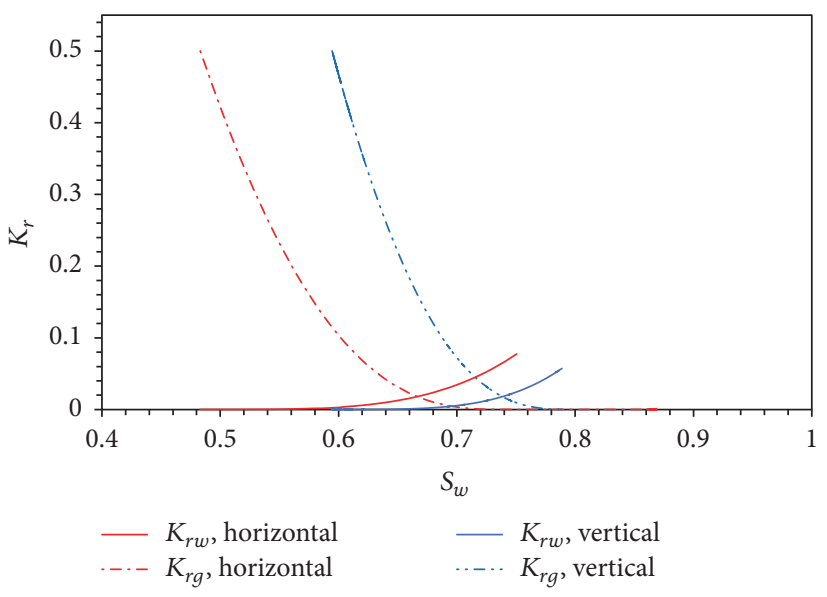

(b)

FIGURE 15: Comparison of relative permeability curves: (a) drainage and (b) imbibition for sample 2.

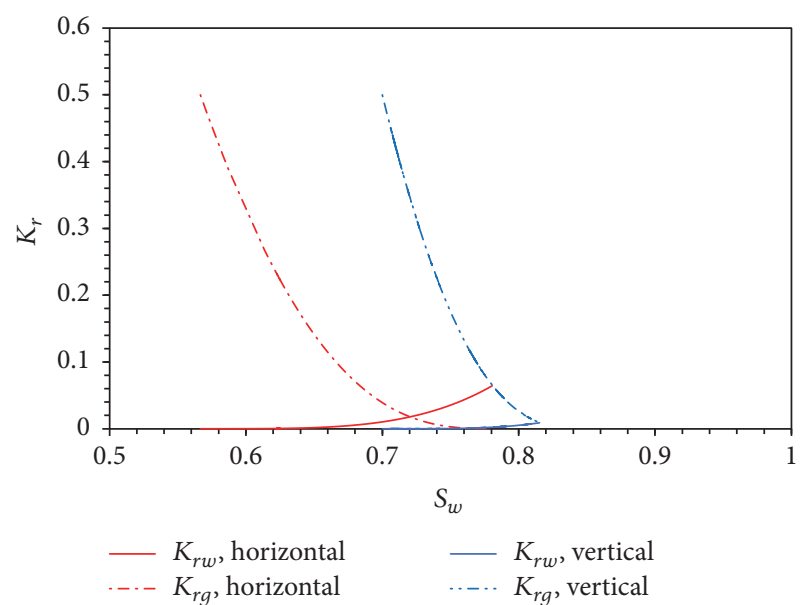

(a)

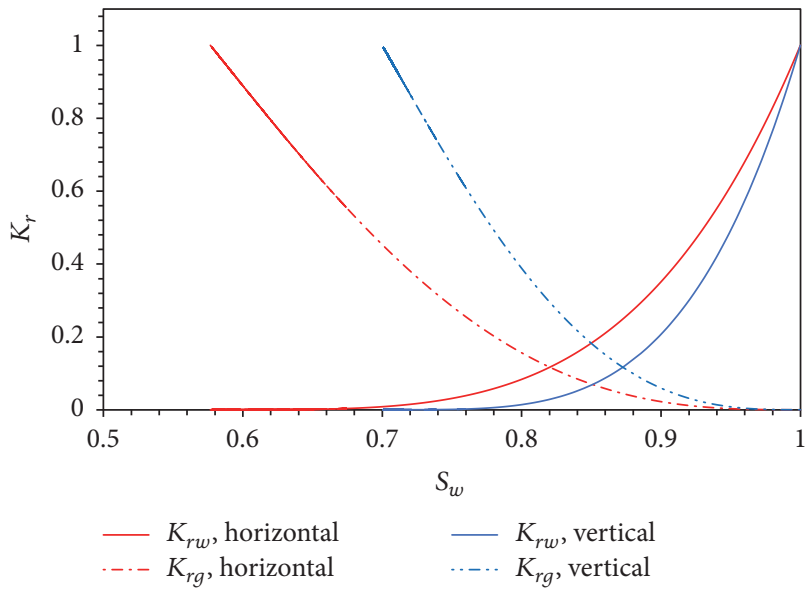

(b)

FIGURE 16: Comparison of relative permeability curves: (a) drainage and (b) imbibition for sample 3.

indicated by the gravity numbers shows that the gravity number is lower in vertical flow than in horizontal flow because of the effect of gravitational fingering and flow against gravity. The gravity number versus residual saturation plot also showed that residual saturation decreases as gravity number increases

(4) Core holder orientation and flow direction in laboratory flow studies are important, since flow direction affects rock and fluid properties such as permeability, residual fluid saturation, and relative permeability. Core orientation should therefore be determined to represent actual reservoir flow.

(5) The higher residual saturation resulting from vertical flow could be taken as an advantage in $\mathrm{CO}_{2}$ sequestration, where higher residual (trapped) gas saturation is desired

(6) Finally, this study underpins the importance of measuring residual saturations, permeability, and relative permeabilities of plug samples in the same direction fluid flows in them during 2D or 3D flow in actual reservoir flow scenarios. Plugs extracted horizontal to the bedding plane should be measured horizontally, while plugs extracted perpendicular to the bedding plane should be measured vertically and the flow in this case should be from bottom to top if the end use of the data is to simulate $\mathrm{CO}_{2}$ migration in the formation. It is thus strongly recommended that reservoir simulation experts understand details of the core flooding experiments used to generate relative permeability curves. They must ensure that the labgenerated relative permeability curves represent the actual flow directions in the reservoir under study.

\section{Conflicts of Interest}

The authors declare that there are no conflicts of interest regarding the publication of this paper. 


\section{Acknowledgments}

The authors acknowledge the Center for Integrative Petroleum Research and College of Petroleum Engineering and Geosciences at King Fahd University of Petroleum \& Minerals for the research support.

\section{References}

[1] A. T. Corey, Mechanics of Heterogeneous Fluids in Porous Media, Water Resources Publications, Fort Collins, Colo, USA, 1977.

[2] M. Honarpour and S. M. Mahmood, "Relative permeability measurements: an overview," Journal of Petroleum technology, vol. 40, no. 8, pp. 963-966, 1988.

[3] B. Bennion and S. Bachu, "Relative permeability characteristics for supercritical $\mathrm{CO}_{2}$ displacing water in a variety of potential sequestration zones in the western canada sedimentary basin," in Proceedings of the SPE Annual Technical Conference and Exhibition, October 2005.

[4] B. Bennion and S. Bachu, "Drainage and imbibition relative permeability relationships for supercritical $\mathrm{CO}_{2}$ /brine and $\mathrm{H}_{2} \mathrm{~S} /$ brine systems in intergranular sandstone, carbonate, shale, and anhydrite rocks," in Paper SPE 99326-MS presented Society of Petroleum Engineers, 2008.

[5] M. Akbarabadi and M. Piri, "Relative permeability hysteresis and capillary trapping characteristics of supercritical $\mathrm{CO}_{2}$ /brine systems: an experimental study at reservoir conditions," Advances in Water Resources, vol. 52, pp. 190-206, 2013.

[6] B. Niu, A. Al-Menhali, and S. Krevor, "A study of residual carbon dioxide trapping in sandstone," in Proceedings of the 12th International Conference on Greenhouse Gas Control Technologies, GHGT 2014, pp. 5522-5529, October 2014.

[7] C. Reynolds, M. Blunt, and S. Krevor, "Impact of reservoir conditions on $\mathrm{CO}_{2}$-brine relative permeability in sandstones," in Proceedings of the 12th International Conference on Greenhouse Gas Control Technologies, GHGT 2014, pp. 5577-5585, October 2014.

[8] J.-C. Perrin, M. Krause, C.-W. Kuo, L. Miljkovic, E. Charoba, and S. M. Benson, "Core-scale experimental study of relative permeability properties of $\mathrm{CO} 2$ and brine in reservoir rocks," in Proceedings of the 9th International Conference on Greenhouse Gas Control Technologies, GHGT-9, pp. 3515-3522, November 2008.

[9] C.-W. Kuo, J.-C. Perrin, and S. M. Benson, "Simulation studies of effect of flow rate and small scale heterogeneity on multiphase flow of $\mathrm{CO}_{2}$ and brine," in Proceedings of the 10th International Conference on Greenhouse Gas Control Technologies, pp. 45164523, September 2010.

[10] C.-W. Kuo and S. M. Benson, "Numerical and analytical study of effects of small scale heterogeneity on CO2/brine multiphase flow system in horizontal corefloods," Advances in Water Resources, vol. 79, pp. 1-17, 2015.

[11] T. Suekane, T. Nobuso, S. Hirai, and M. Kiyota, "Geological storage of carbon dioxide by residual gas and solubility trapping," International Journal of Greenhouse Gas Control, vol. 2, no. 1, pp. 58-64, 2008.

[12] A. T. Corey and C. H. Rathjens, "Effect of stratification on relative permeability," Society of Petroleum Engineers, vol. 8, no. 12,1956

[13] M. M. Honarpour and N. Saad, "Influence of small-scale rock laminations on core plug oil/water relative permeability and capillary pressure, society of petroleum engineers," Society of Petroleum Engineers, 1994.

[14] M. M. Honarpour, A. S. Cullick, N. Saad, and N. V. Humphreys, "Effect of Rock Heterogeneity on Relative Permeability: Implications for Scale-up , Society of Petroleum Engineers," Tech. Rep. 10., Society of Petroleum Engineers. doi, 10.2118/29311-PA, 1995.

[15] M. A. Crotti and J. A. Rosbaco, "Relative permeability curves: the influence of flow direction and heterogeneities," Society of Petroleum Engineers, 1998.

[16] R. A. Fulcher, T. Ertekin, and C. D. Stahl, "Effect of capillary number and its constituents on two-phase relative permeability curves," Society of Petroleum Engineers, vol. 37, no. 2, 1985.

[17] D. Zhou, F. J. Fayers, and F. M. Orr, "Scaling of multiphase flow in simple heterogeneous porous media," Society of Petroleum Engineers, vol. 12, no. 3, 1997.

[18] K. Chia-Wei and M. Sally, "Analytical study of effects of flow rate, capillarity, and gravity on $\mathrm{CO}_{2}$ /brine multiphase-flow system in horizontal corefloods," SPE Journal, vol. 92, no. IR2, pp. 61-88, 2013.

[19] C. A. Reynolds and S. Krevor, "Characterizing flow behavior for gas injection: relative permeability of $\mathrm{CO}_{2}$-brine and $\mathrm{N}_{2}$-water in heterogeneous rocks," Water Resources Research, vol. 51, no. 12, pp. 9464-9489, 2015.

[20] A. T. Corey, "The Interrelation between gas and oil relative permeabilities," Producers Monthly, vol. 19, p. 38, 1954.

[21] J. Naar and J. H. Henderson, "An imbibition model-its application to flow behavior and the prediction of oil recovery: society of petroleum engineers,' Society of Petroleum Engineers, vol. 1, no. 2,1961 .

[22] R. H. Brooks and A. T. Corey, "Properties of porous media affecting fluid flow," Journal of the Irrigation and Drainage Division, vol. 92, no. IR2, pp. 61-88, 1966.

[23] G. P. Willhite, Waterflooding, Society of Petroleum Engineers, Richardson, TX, USA, 1986.

[24] J. B. Moortgat, A. Firoozabadi, Z. Li, R. O. Esp, and R. O. Espósito, " $\mathrm{CO}_{2}$ Injection in Vertical and Horizontal Cores: Measurements and Numerical Simulation," Society of Petroleum Engineers, vol. 18, no. 2, Article ID 135563, 2013. 

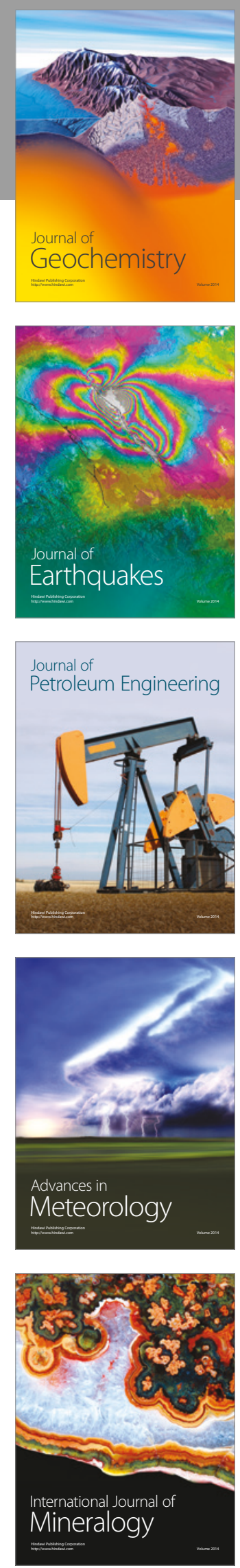
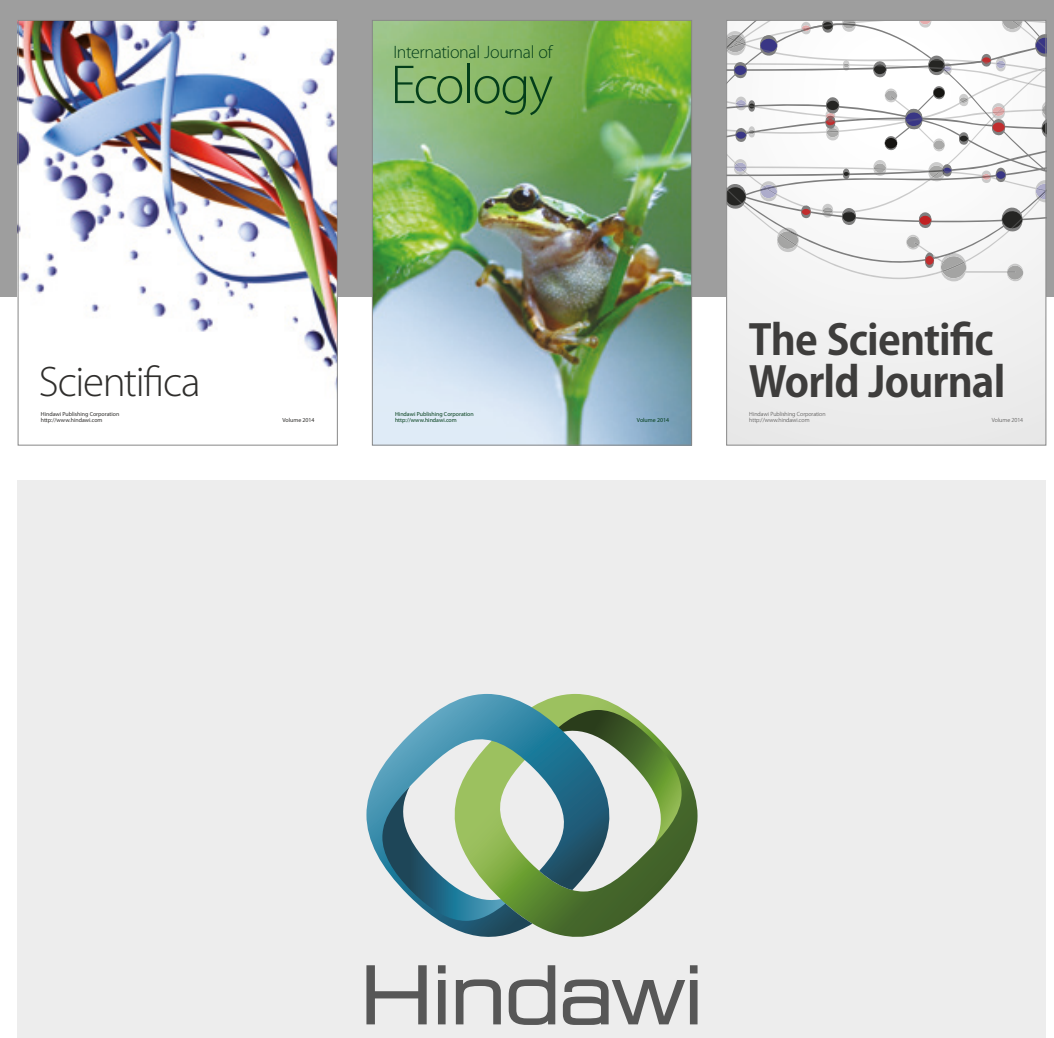

Submit your manuscripts at

https://www.hindawi.com
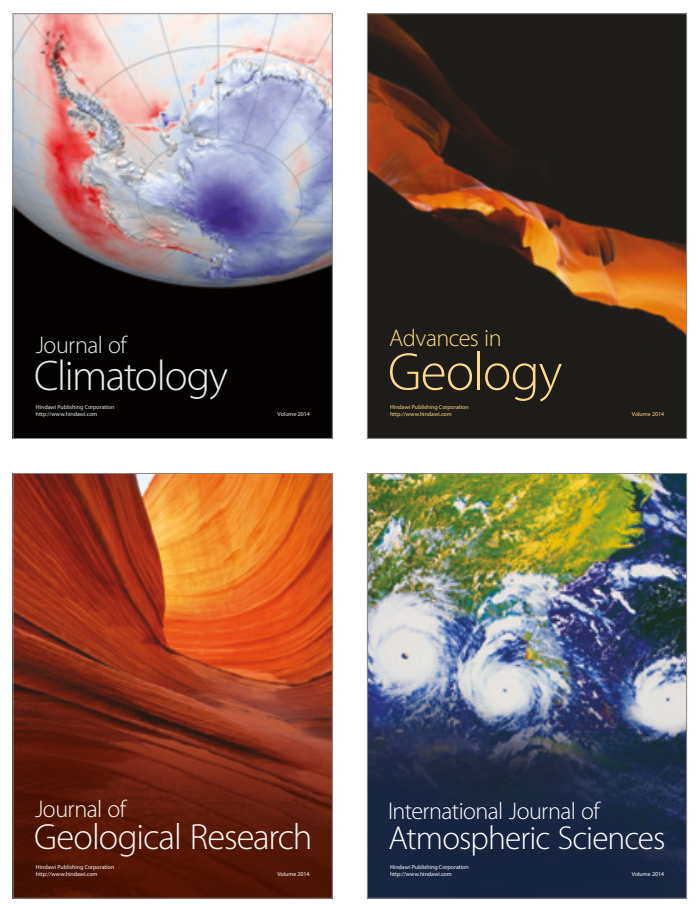

The Scientific

World Journal
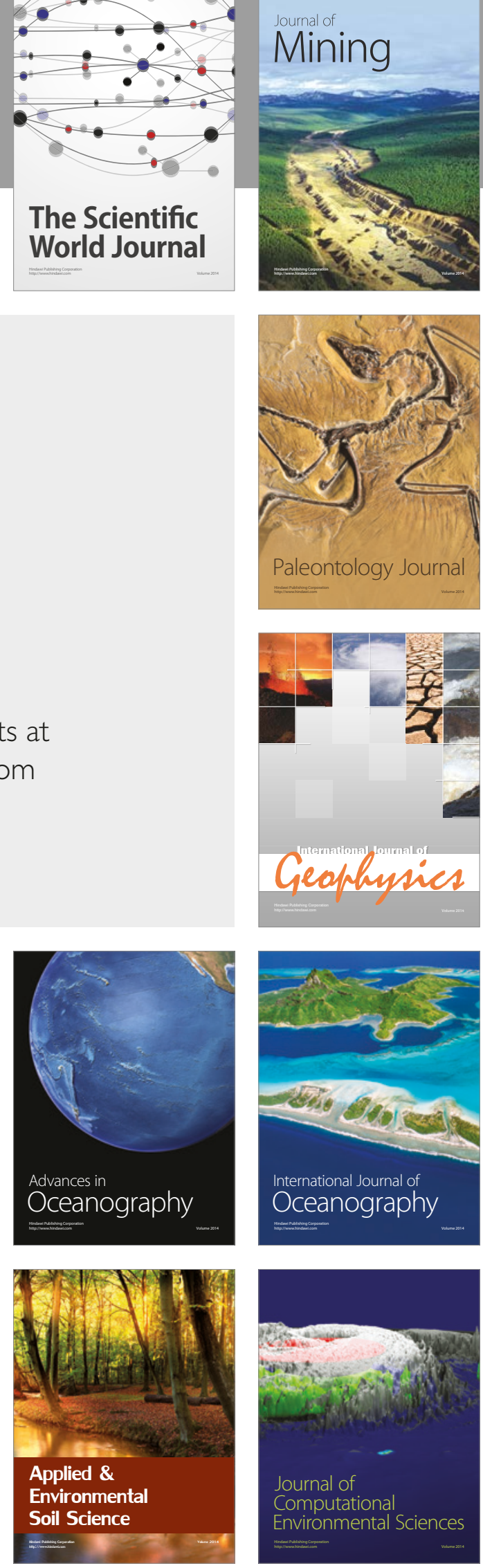